\title{
Parámetros productivos y morfológicos en pollos parrilleros suplementados con ácidos orgánicos y levadura
}

\author{
Nicoletti, D. '; Flores Quintana, C.'; Terraes, J. ${ }^{2}$ Kuttel, J. ${ }^{2}$ \\ ${ }^{1}$ Cátedra de Histología y Embriología, ${ }^{2}$ Cátedra de Producción de Aves, Facultad de Ciencias Veterinarias, \\ UNNE, Sargento Cabral 2139, Corrientes (3400), Argentina. Tel: 03783-425753. \\ E-mail: carolina@vet.unne.edu.ar.
}

\begin{abstract}
Resumen
Nicoletti, D.; Flores Quintana, C.; Terraes, J.; Kuttel, J.: Parámetros productivos y morfológicos en pollos parrilleros suplementados con ácidos orgánicos y levadura. Rev. vet. 21: 1, 23-27, 2010. La prohibición del uso de antibióticos promotores del crecimiento en pollos, determina la búsqueda de alternativas que disminuyan la susceptibilidad de los animales a las condiciones del medio ambiente y que cubran la pérdida de rusticidad lograda con la mejoría de los índices productivos. Una opción es el uso de sustancias prebióticas (extractos de levaduras, ácidos orgánicos y otros principios) que actúan a nivel intestinal optimizando su función (digestión, absorción, mecanismos de defensa). El objetivo del presente trabajo fue analizar parámetros productivos y morfológicos en un lote de pollos parrilleros alimentados con una dieta convencional versus otro suplementado con extracto de pared de levadura y ácidos orgánicos. Se llevó a cabo la cría de pollos parrilleros machos desde su nacimiento hasta el día 42, en galpón cerrado. Semanalmente se registraron los promedios de peso corporal, consumo de alimento y conversión alimenticia. Los días 7, 14, 21, 28 y 35 se sacrificaron pollos para obtener muestras de duodeno y yeyuno-ileon. Las aves que consumieron la dieta suplementada presentaron índices productivos significativamente más altos a los del grupo control. En cambio, las vellosidades intestinales fueron mayores en los pollos alimentados con la dieta control. Durante las tres primeras semanas del ciclo, las criptas duodenales fueron más profundas en el grupo suplementado, variable que no registró cambios en los controles. La suplementación mejoró los parámetros productivos analizados, pero el efecto trófico sobre la mucosa intestinal debería ser objeto de nuevos estudios que incluyan otros elementos estructurales y funcionales capaces de explicar la mejoría productiva alcanzada en el ensayo.
\end{abstract}

Palabras clave: pollo parrillero, prebiótico, índices productivos, cambios intestinales.

\begin{abstract}
Nicoletti, D.; Flores Quintana, C.; Terraes, J.; Kuttel, J.: Productive and morphological parameters in broilers supplemented with organic acids and yeast. Rev. vet. 21: 1, 23-27, 2010. The prohibition of the use of antibiotic growth promoters in chickens determines the research of alternatives that decrease the susceptibility of animals to environmental conditions and lost of rusticity achieved as a consequence of the improvement of productive rates. One alternative is the use of prebiotic substances (yeast extracts, organic acids and other compounds) acting as promoters of the intestinal function (digestion, absorption and defense mechanisms). The aim of this assay was to analyze productive as well as morphological variables in broilers fed on a conventional diet versus another supplemented with yeast wall extracts and organic acids. Broiler male chickens were bred from hatching until day 42 in a broiler shed. Data on body weight average, feed intake and feed conversion were registered weekly. On days 7, 14, 21, 28 and 35 animals were euthanized to obtain samples from duodenal and jejunum-ileum tissues. Birds fed on formulated diet showed significantly higher productive rates compared to the control group. The duodenal and jejunum-ileum villus were higher in chickens fed on control diet. The duodenal crypts were deeper in supplemented group during the first three weeks of the cycle, whereas for the jejunum-ileum region no significant changes were observed. Supplementation improved all the studied productive parameters, although the trophic effect on the mucosa was detected only during the first week after hatching.
\end{abstract}

Key words: broiler, prebiotic, productive indexes, intestinal changes. 


\section{INTRODUCCIÓN}

El pollo parrillero se caracteriza por su velocidad de crecimiento, conformación y rendimiento de la canal ${ }^{16}$. Las estirpes actuales son más susceptibles a las condiciones del medio ambiente y esta pérdida de rusticidad ha seguido una relación inversamente proporcional a las mejoras logradas en los índices de la producción ${ }^{5}$. La fragilidad metabólica y la mayor propensión al estrés, sumadas a la intensificación de las prácticas de manejo actual, afectan la salud productiva del lote y ocasionan frecuentemente enfermedades que se originan en el desequilibrio existente entre el rápido crecimiento de los tejidos osteomusculares y la incapacidad de los sistemas cardiovascular, respiratorio, digestivo e inmune para atender esa demanda. Por esta razón, la práctica avícola generalizó el uso de los antibióticos promotores del crecimiento (APC) a fin de promover y consolidar el desarrollo de las aves, en particular el del aparato digestivo.

Actualmente, la prohibición del uso de los APC obliga a la producción avícola a buscar soluciones alternativas en cuanto al manejo, prevención sanitaria, ajustes en la composición de las raciones o inclusión de aditivos en las mismas. Dentro de estas opciones se incluyen los ácidos orgánicos, enzimas., probióticos y prebióticos.

Los oligosacáridos del tipo manano-oligosacárido (MOS) provienen de la pared celular de levaduras (Saccharomyces cerevisiae) y llegan intactos hasta el segmento intestinal donde serán sustrato para la flora bacteriana allí presente. Producen bloqueo de bacterias patógenas "secuestrándolas", impidiendo su unión con receptores constituidos por carbohidratos presentes en los enterocitos, unión que constituye un paso esencial en la patogénesis de muchas enfermedades. Sin la competencia de las bacterias, el hospedador tiene mayor cantidad de nutrientes y energía disponibles para la absorción y metabolismo ${ }^{3}$.

Además, los MOS mejoran la digestibilidad y capacidad de absorción de los nutrientes al propiciar el adecuado equilibrio de la población microbiana, favoreciendo el desarrollo de flora banal, obviamente sin riesgos para la salud del consumidor ${ }^{7}$. Producen aglutinación de ciertos gérmenes patógenos en el medio intestinal ${ }^{15}$; constituyen un sustrato específico rápidamente disponible en el tracto intestinal para una amplia gama de bacterias acidófilas, lo que incrementa la tasa de multiplicación de estas cepas y la producción de los ácidos orgánicos resultantes de su metabolismo; provoca una mejoría en la condición de la mucosa intestinal, y estimula el sistema inmune local, incrementando la eficacia de la barrera intestinal ante la agresión de patógenos ${ }^{6}$.

La medición de variables zootécnicas como único indicador de la eficacia de estos aditivos es, en muchas ocasiones, poco efectiva. Por ello se busca desarrollar técnicas más sensibles, algunas basadas en la cuantificación de fragmentos de DNA para detectar cambios en la microflora intestinal y otras evaluando las modi-
Tabla 1. Composición química de las raciones suministradas a los pollos.

\begin{tabular}{lcc}
\hline nutrientes & iniciador & terminador \\
\hline energía - E.met./ kg & 3.100 & 3.200 \\
proteína (\%) & 23 & 18,5 \\
lisina (\%) & 1,2 & 0,94 \\
metionina (\%) & 0,47 & 0,38 \\
metionina-cistina & 0,92 & 0,77 \\
arginina (\%) & 1,28 & 0,96 \\
triptófano (\%) & 0,22 & 0,18 \\
calcio (\%) & $0,90-0,95$ & $0,80-0,85$ \\
fósforo (\%) & 0,45 & 0,40 \\
sodio (\%) & $0,18-0,20$ & $0,18-0,22$ \\
\hline
\end{tabular}

ficaciones del ambiente físicoquímico, bacteriológico e histológico del tracto gastrointestinal, correlacionando dichas variables con las de producción.

El objetivo de este trabajo fue analizar el efecto que produce la incorporación de ácidos orgánicos de cadena corta con extractos altamente purificados de pared de levadura en la dieta de pollos parrilleros mediante el uso de variables productivas conjuntamente con características morfológicas del tracto digestivo.

\section{MATERIAL Y MÉTODOS}

El trabajo se realizó en galpón cerrado subdividido en 14 boxes de $2 \mathrm{~m}^{2}$. En cada box fueron alojados 11 pollos parrilleros de la línea Cobb 500 autosexantes por gen de emplume lento. El ciclo duró 42 días y el tratamiento consistió en el suministro de una dieta control (sin antibióticos ni coccidiostatos) y una dieta similar a la anterior pero suplementada con un producto comercial que contiene una combinación de ácidos y sales de ácidos orgánicos específicos (fórmico, acético, formiato y propionato de amonio) y pared de levadura purificada (Saccharomyces cerevisiae), vehiculizados en una matriz mineral activa. Dicho suplemento se agregó en proporción de $1,5 \mathrm{~kg} / \mathrm{tn}$ de alimento en ambas fases. Las raciones fueron formuladas según recomendaciones nutricionales correspondientes para dieta de pollos parrilleros (Tabla 1).

Semanalmente se obtuvo el peso corporal, consumo de alimento: total de alimento consumido (en $\mathrm{kg}$ ) en cada box / número de aves y conversión alimenticia: cociente entre consumo / peso corporal. Se faenó un parrillero por box, siete por tratamiento, los días 7, 14, 21,28 y 35 , siguiendo las directrices para el sacrificio de animales de la OIE dentro del código sanitario para animales terrestres. En la faena, se procedió al retiro del tubo digestivo, obteniéndose de cada ejemplar una muestra de duodeno y otra de yeyuno-íleon que se fijaron en solución de Bouin y posteriormente se sometieron al procesamiento histológico de rutina. Se realizaron cortes semi-seriados que se colorearon con hematoxilina y eosina.

Se obtuvieron 6 registros fotográficos de cada una de las muestras de los segmentos intestinales y sobre 
cada imagen se determinó la altura de las vellosidades intestinales (distancia entre el borde apical de las mismas y la zona de unión con la cripta) y la profundidad de las criptas (distancia de la invaginación entre dos vellosidades ${ }^{1}$ ), utilizándose el software Image-ProPlus, versión 4.5 Media Cybernetics Inc.

Para cada una de las variables dependientes se realizó estadística descriptiva paramétrica, por tratamientos. Se aplicó análisis de la varianza (ANOVA) para un diseño completamente al azar, evaluando las diferencias entre tratamientos de las variables dependientes y las relaciones entre ellas (correlación de Pearson), considerando límite un nivel de significancia del $5 \%{ }^{11}$.

\section{RESULTADOS}

A lo largo del ciclo, el promedio del peso corporal de los pollos suplementados fue superior y significativamente diferente al de los alimentados con la dieta control, con excepción del día 42 (Tabla 1).

Se registró mayor consumo en pollos suplementados, con diferencia significativa en el día 28 del ciclo (Tabla 2).

En cuanto a la conversión alimenticia, en la Tabla 3 se presentan los resultados obtenidos, surgiendo que se registraron diferencias significativas entre grupos en las observaciones realizadas a los días 14 y 21 .

El comportamiento de la altura de las vellosidades intestinales a nivel del duodeno fue diferente a lo largo del ciclo (Tabla 4). A los 7 días, las vellosidades en los pollos del grupo suplementado presentaron valores significativamente superiores a los del grupo control (Figura 1); sin embargo dicha respuesta posteriormente se invirtió, alcanzando significancia estadística en el día 21 del ciclo.

La altura de las vellosidades en el segmento yeyuno-ileon siempre fue superior en las aves control (Figura 2), con diferencias significativas en 3 momentos del ciclo: días 14, 21 y 28 (Tabla 5).

Con respecto a la profundidad de las criptas duodenales (Figura 3), se registraron valores promedios superiores en el grupo suplementado, aunque la diferencia fue significativa solo durante las 3 primeras semanas del ciclo (Tabla 6). En la región yeyuno-ileon, no se observaron diferencias significativas entre tratamientos. En las aves suplementadas las criptas fueron mas profundas los días 7, 14 y 28, sin embargo los valores fueron inversos los días 21 y 35 del ciclo.
Tabla 1. Evolución del peso corporal (g) a lo largo del ciclo según tratamientos.

\begin{tabular}{lccccccc}
\hline días & 0 & $7 *$ & $14 *$ & $21 *$ & $28 *$ & $35 *$ & 42 \\
\hline grupo control & 42,5 & 149,1 & 369,8 & 786,0 & 1.302 & 1.936 & 2.716 \\
$\overline{\mathrm{X}} \pm \mathrm{DE}$ & $\pm 0,80$ & $\pm 9,0$ & $\pm 17,7$ & $\pm 19,6$ & $\pm 77,3$ & \pm 103 & \pm 158 \\
grupo suplem. & 43,3 & 160,3 & 398,5 & 848,5 & 1.416 & 2.050 & 2.822 \\
$\overline{\mathrm{X}} \pm \mathrm{DE}$ & $\pm 1,3$ & $\pm 8,3$ & $\pm 17,7$ & $\pm 33,1$ & $\pm 54,6$ & $\pm 63,4$ & \pm 73 \\
\hline
\end{tabular}

$\overline{\mathrm{X}}$ : media aritmética, DE: desvío estándar, *valores estadísticamente dife-

Tabla 2. Consumo acumulado de alimento (g) a lo largo del ciclo según tratamientos.

\begin{tabular}{lcccccc}
\hline días & 7 & 14 & 21 & $28^{*}$ & 35 & 42 \\
\hline grupo control & 162,7 & 540 & 1.199 & 2.140 & 3.392 & 4.931 \\
$\overline{\mathrm{X}} \pm \mathrm{DE}$ & $\pm 5,14$ & $\pm 12,99$ & $\pm 23,93$ & $\pm 96,86$ & $\pm 162,87$ & $\pm 199,05$ \\
grupo suplem. & 166,7 & 547 & 1.232 & 2.255 & 3.483 & 5.058 \\
$\overline{\mathrm{X}} \pm \mathrm{DE}$ & $\pm 2,45$ & $\pm 25,85$ & $\pm 50,84$ & $\pm 64,70$ & $\pm 139,00$ & $\pm 232,96$
\end{tabular}

$\overline{\mathrm{X}}$ : media aritmética, DE: desvío estándar, *valores estadísticamente diferentes con un nivel de significancia (alfa) del $5 \%$.

Tabla 3. Conversión alimenticia acumulada a lo largo del ciclo según tratamientos.

\begin{tabular}{lcccccc}
\hline días & 7 & $14^{*}$ & $21^{*}$ & 28 & 35 & 42 \\
\hline grupo control & 1,0 & 1,4 & 1,5 & 1,6 & 1,7 & 1,82 \\
$\overline{\mathrm{X}} \pm \mathrm{DE}$ & $\pm 0,08$ & $\pm 0,04$ & $\pm 0,03$ & $\pm 0,06$ & $\pm 0,05$ & $\pm 0,15$ \\
grupo suplem. & 1,0 & 1,3 & 1,4 & 1,5 & 1,7 & 1,77 \\
$\overline{\mathrm{X}} \pm \mathrm{DE}$ & $\pm 0,05$ & $\pm 0,07$ & $\pm 0,07$ & $\pm 0,04$ & $\pm 0,10$ & $\pm 0,08$ \\
\hline
\end{tabular}

X: media aritmética, DE: desvío estándar, *valores estadísticamente dife-

Tabla 4. Altura de vellosidades $(\mu \mathrm{m})$ en duodeno de pollos controles y suplementados.

\begin{tabular}{lccccc}
\hline días & $7 *$ & 14 & $21^{*}$ & 28 & 35 \\
\hline grupo control & $1.149,3$ & $1.562,1$ & $1.703,5$ & $1.871,2$ & $1.965,3$ \\
$\overline{\mathrm{X}} \pm \mathrm{DE}$ & $\pm 107,5$ & $\pm 181,2$ & $\pm 133,0$ & $\pm 194,7$ & $\pm 196,3$ \\
& & & & & \\
grupo suplem. & $1.220,4$ & $1.521,1$ & $1.669,8$ & $1.846,3$ & $1.923,8$ \\
$\overline{\mathrm{X}} \pm \mathrm{DE}$ & $\pm 165,0$ & $\pm 256,0$ & $\pm 216,5$ & $\pm 157,4$ & $\pm 243,1$ \\
\hline
\end{tabular}

$\overline{\mathrm{x}}$ : media aritmética, DE: desvío estándar, *valores estadísticamente diferentes con un nivel de significancia (alfa) del 5\%.

\section{DISCUSIÓN}

Con excepción del día 42, los pesos corporales fueron significativamente superiores en el grupo suplementado, en contraposición a lo observado por otros investigadores, quienes no hallaron diferencias en el peso, consumo y conversión alimenticia, usando como fuente de oligosacáridos el extracto de levadura de cerveza en un ciclo de 50 días ${ }^{8}$. Sin embargo, hay trabajos que muestran mejorías significativas en el peso vivo y la conversión alimenticia de pollos suplementados con MOS en cantidades semejantes a las utilizadas en este ensayo ${ }^{4}$. Los resultados también fueron similares a los obtenidos con dietas adicionadas con bacitracina e in- 
Tabla 5. Altura de vellosidades $(\mu \mathrm{m})$ en yeyuno-íleon de controles y suplementados.

\begin{tabular}{lccccc}
\hline días & 7 & $14 *$ & $21^{*}$ & $28^{*}$ & 35 \\
grupo control & 556,5 & 708,7 & $1.017,9$ & $1.213,5$ & $1.342,5$ \\
$\overline{\mathrm{X}} \pm \mathrm{DE}$ & $\pm 148,1$ & $\pm 114,9$ & $\pm 148,7$ & $\pm 200,9$ & $\pm 236,2$ \\
grupo suplem. & 542,2 & 633,2 & 899,4 & $1.150,9$ & $1.313,2$ \\
$\overline{\mathrm{X}} \pm \mathrm{DE}$ & $91,6 \pm$ & $\pm 66,9$ & $\pm 115,2$ & $\pm 157,4$ & $\pm 241,3$ \\
\hline
\end{tabular}

$\overline{\mathrm{X}}$ : media aritmética, DE: desvío estándar, *valores estadísticamente diferentes con un nivel de significancia (alfa) del 5\%.

Tabla 6. Profundidad de criptas duodenales $(\mu \mathrm{m})$ en pollos controles y suplementados.

\begin{tabular}{lccccc}
\hline días & $7 *$ & $14 *$ & $21 *$ & 28 & 35 \\
\hline grupo control & 180,7 & 269,9 & 271,3 & 316,6 & 375,7 \\
$\overline{\mathrm{X}} \pm \mathrm{DE}$ & $\pm 37,1$ & $\pm 51,5$ & $\pm 47,3$ & $\pm 47,5$ & $\pm 46,4$ \\
grupo suplem. & 206,2 & 297,3 & 286,3 & 317,2 & 378,3 \\
$\overline{\mathrm{X}} \pm \mathrm{DE}$ & $\pm 41,5$ & 46,7 & $\pm 52,9$ & $\pm 58,7$ & $\pm 64,7$ \\
\hline
\end{tabular}

$\overline{\mathrm{X}}$ : media aritmética, DE: desvío estándar, "valores estadísticamente diferentes con un nivel de significancia (alfa) del 5\%.

clusive la respuesta fue similar en pavos suplementados con cantidades variables de $\mathrm{MOS}^{7}$.

Los resultados registrados en la bibliografía especializada toman en cuenta diferencias obtenidas en la ganancia diaria media y conversión alimenticia utilizando APC y otros productos alternativos ${ }^{13}$. Se destacan mejorías de $10,8 \mathrm{~g}$ y $3,4 \%$ en las variables citadas para el caso de los APC; 7,1 g y 2,8\% para los ácidos orgánicos; $3,1 \mathrm{~g}$ y $1,1 \%$ en promedio para oligosacáridos y $9,5 \mathrm{~g}$ y $3,3 \%$ para el caso de la mezcla de productos alternativos a los APC. Para la conversión alimenticia, los resultados aquí obtenidos con la dieta suplementada coinciden casi exactamente a lo observado por otro autor para la mezcla de productos ${ }^{13}$.

Algunos trabajos detectaron mayor peso corporal en aves suplementadas con MOS solo a los 42 días ${ }^{2}$. Esto difiere con los resultados obtenidos en este ensayo, donde se detectaron diferencias significativas en el peso corporal a lo largo del ciclo y únicamente diferencias numéricas $(\mathrm{p}=0,07)$ a los 42 días. Sin embargo, hay ensayos que destacan de forma diferencial el comportamiento de las variables productivas vinculadas a la edad de los animales. Durante las primeras etapas del
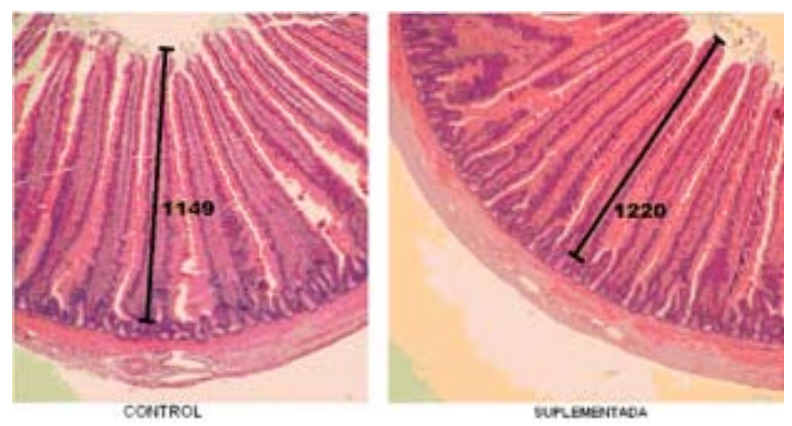

Figura 1. Duodeno: altura de vellosidades intestinales $(\mu \mathrm{m})$ a los 7 días de edad. ciclo de producción, 21 primeros días, las aves suplementadas con MOS fueron mas eficientes que las aves del grupo control e incluso que las suplementadas con APC 7 .

Varios autores consideran que ciertas variables histológicas del intestino de las aves correlacionan con adecuados grados de función del órgano y por lo tanto, con un óptimo desempeño productivo del ave. La morfología del tubo digestivo de aves suplementadas con extracto purificado de pared de levadura y beta-1,3/1,6-glucano evaluada por segmentos, mostró a los 21 días del ciclo, diferencias significativas en la altura de las vellosidades de yeyuno en las aves suplementadas ${ }^{9}$. La altura de las vellosidades en duodeno fue significativamente mayor en los controles respecto a MOS y MOS+ácido (1.539, 1.401 y 1.366 um respectivamente) y en yeyuno se detectaron diferencias significativas entre tratamientos, en el siguiente orden, MOS+ácido (1.271 um), MOS (1.218 um) y control $(1.131 \mathrm{um})^{10}$. En la presente investigación, tanto en duodeno como yeyuno, los animales del grupo control presentaron valores de profundidad de las criptas intestinales significativamente superiores respecto a los suplementados, que no mostraron diferencias entre sí.

Los resultados aquí obtenidos no coinciden con los de algunos trabajos ${ }^{9,10}$, ya que a pesar de haberse constatado mejorías significativas en el comportamiento productivo de las aves suplementadas, la mayoría de las variables asociadas a la morfología intestinal, particularmente altura de vellosidades, presentaron un

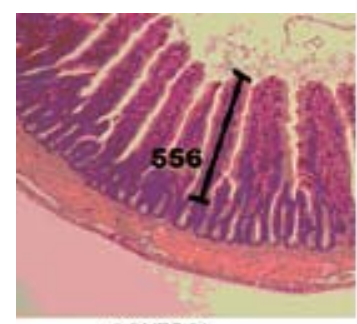

CONTROL

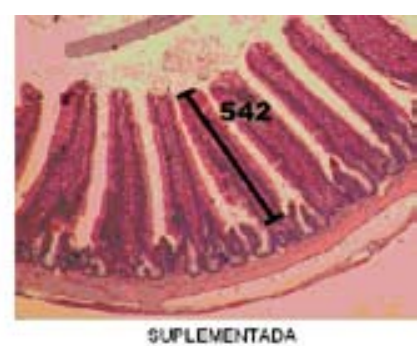

SUPLCVENTADA
Figura 2. Yeyuno-ileon: altura de vellosidades intestinales $(\mu \mathrm{m})$ a los 7 días de edad.
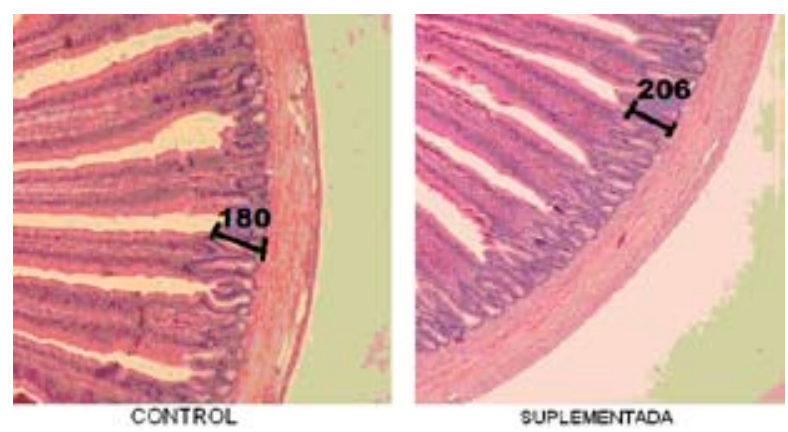

Figura 3. Profundidad de las criptas duodenales (um) a los 7 días de edad. 
menor grado de desarrollo en este grupo, existiendo variaciones en la respuesta en función del tratamiento, de la variable considerada, del sector del intestino y de la edad del ciclo a la que se hace referencia.

Sin embargo, estos resultados coinciden con quienes constatan que la altura de las vellosidades intestinales de las aves suplementadas fue similar o menor a la del grupo control, a pesar de registrarse mejorías significativas en las variables productivas ${ }^{12}$. El incremento de la altura de las vellosidades intestinales en el duodeno hacia el día 7 de vida en aves suplementadas con MOS sugiriere un efecto trófico indirecto sobre la mucosa duodenal, que se expresa además con un aumento en el grosor de la pared del duodeno ${ }^{12}$. Esto último se traduciría en una mejor calidad de la respuesta secretoria de la mucosa, lo que favorece significativamente el proceso digestivo que ocurre con gran intensidad en este sector del intestino de las aves.

Con respecto a la profundidad de cripta y a diferencia de lo observado en este trabajo, algunos autores demostraron reducción en la profundidad de las mismas con incremento de la relación largo de vellosidades / profundidad de criptas ${ }^{14}$, aunque no señalaron la porción del intestino a que se refieren.

Concluyendo, los resultados de este trabajo muestran que la suplementación mejoró los parámetros productivos analizados. Sin embargo, teniendo en cuenta la morfología intestinal, el efecto trófico sobre la mucosa solo se detectó en la primera semana de vida. Por ello se considera necesaria la realización de nuevos estudios, con inclusión de otros elementos estructurales y funcionales que intervienen en la salud de la luz intestinal, de manera tal que puedan explicar las mejorías alcanzadas a lo largo del ciclo productivo.

\section{REFERENCIAS}

1. Awad W, Khaled G, Böhm J. 2008. Intestinal structure and function of broiler chickens on diets supplemented with a synbiotic containing Enterococcus faecium and oligosaccharides. Int J Mol Sci 9: 2205-2216.

2. Benites V, Gilharry R, Gernat AG, Murillo JG. 2008. Effect of dietary mannan oligosaccharide from bio-mos or saf-mannan on live performance of broiler chickens. $J$ Appl Poul Res 17: 471-475.

3. Ferket PR, Parks CW, Grimes JL. 2008. Oligosacáridos mananos versus antibióticos para pavos. Informe Departamento Ciencia Aviar, North Carolina State University, Raleigh (USA). On line: http://www.engormix.com.

4. Hooge D, Sims M, Sefton A, Connolly A, Spring P. 2003. Effect of dietary mannan oligosaccharide, with or without bacitracin or virginiamycin, on live performance of broiler chickens at relatively high stocking density on new litter. $J$ Appl Poult Res 12: 461-467.

5. Lleonart F, Cifuentes E, Callis M, Gurri A, Pontes M. 1991. Higiene y patología aviares, Ed. Real Escuela de Avicultura, Barcelona, $421 \mathrm{p}$.

6. Loddi M, Nakaghi L, Edens F, Tucci F, Hannas M, Moraes V, Ariki J. 2002. Mannanoligosaccharide and organic acids on intestinal morphology integrity of broilers evaluated by scanning electron microscopy. Proc. 11th Eur Poult Sci Conf, Bremen, Germany, p. 121.

7. Maiorka A, Dahlde F. 2008. Avaliacao de diferentes aditivos para dietas de frangos de corte. Relatorio final de investigación, Ministerio de Educacao, Universidade Nacional do Paraná, Curitiba (Brasil).

8. Miazzo R, Peralta M, Nilson C, Picco M. 2007. Calidad de la canal de broilers que recibieron levadura de cerveza (S. cerevisiae) en las etapas de iniciación y terminación. Anales $X X^{\circ}$ Congreso Latinoamericano de Avicultura, Porto Alegre, Brasil, NU 36.

9. Morales R, Auclair E, García F, Esteve E, Brufau J. 2009. Use of yeast cell walls; beta-1, 3/1, 6-glucans; and mannoproteins in broiler chicken diets. Poult Sci 88:601607.

10. Pelicano E, Souza P, Souza H, Figueiredo D, Boiago M, Bordon V. Carvalho S. 2005. Intestinal mucosa development in broiler chickens fed natural growth promoters. Braz J Poult Sci 7: 221-229.

11. Poole R. 1974. Sampling and the estimation of population parameters. An introduction to quantitative ecology, McGraw Hill, New York, p. 292-324.

12. Santin E, Maiorka A, Macari M, Grecco M, Sanchez JC, Okada TM, Myasaka AM. 2001. Performance and intestinal mucosa development in broiler chickens fed ration containing Saccharomyces cerevisiae Cell Wall J Appl Poult Res 10: 236-244.

13. Santomá G. 1999. Aditivos alternativos a los antibióticos y promotores de crecimiento. Memorias XXXVI Symp Avicult WPSA, Valladolid (España), p. 95-132.

14. Savage T, Zakrzewska E. 1996. The performance of male turkeys fed a starter diet containing a mannanoligosaccharid (Bio-Mos) from day old to eight weeks of age. Proc Alltech's 12th Ann Symp Biotechnol Feed Ind, Loughborough (UK), p. 47-54.

15. Spring PC, Wenk KA, Dawson C, Newman K. 2000. Effect of mannan oligosaccharide on different cecal parameters and on cecal concentration of enteric bacteria in challenged broiler chicks. Poult Sci 79: 205-211.

16. Urrutia S. 2000. El broiler del año 2001. Rev Avic Prof 15: 23-28. 